\title{
University professor's assessment in the conditions of digital transformation
}

\author{
Tatiana Isaeva*, Iuliia Kotliarenko, and Lyubov Cherkasova \\ Rostov State Transport University, 344038, Rostov-on-Don, Russia
}

\begin{abstract}
Professional and personal competences of a university professor are considered not only as one of the theoretical directions of pedagogical research, but also as a factor in ensuring the quality of modern higher education. Despite the constant efforts of individual researchers and international organizations dealing with educational problems on a global scale, the composition of the unified system of professor's competences has not been drawn up yet due to the differences in national, methodological and practical approaches. The task of assessing a university professor, determining the degree of effectiveness of his educational and research activities is no less urgent. In connection with the existing tendency in modern pedagogy to assess a professor by means of the identification of his competences, the article analyses the changes in the basic competences that occurred during the period of forced remote learning. As a result of using a number of theoretical and empirical research methods, the most popular tools and techniques for assessing the professor's performance have been identified, the attitude of the professors to the use of these methods and the objectivity of experts has been demonstrated. The directions of modernization of methods, which can be used to assess the work of university professors on the basis of modern electronic technologies in the context of digitalization of education are outlined.
\end{abstract}

\section{Introduction}

In recent years, there have been great changes in the hierarchy of requirements for the professional activity of a university professor. First of all, they were caused by the actualization of the role of scientific research in the professors' work, which is due to the governmental tasks in the digitalization of the economy, development of innovative scientific branches and advanced technologies. Earlier, educational activity was of greater importance for professors of Russian universities, and if we talk about the period before the 1990 s, priority was given to upbringing of young people [1] in order to instill in them the ideological attitudes and values of the so-called "Soviet era".

In the article, we purposefully use the word "professor" to designate all positions of university scientific and pedagogical faculty, which is typical for English-language texts, so as not to be confused with the work of secondary school teachers.

* Corresponding author: isaeva.te@yandex.ru 
Even greater changes took place in the work of the university professors during the period of the forced remote learning in March 2020 - February 2021. During this period, the professors managed to form completely new competencies in a very short time, as well as some changes took place in the previously existing ones [2].

However, despite of such important changes in the activities of a university professor, the system for assessment the effectiveness of his/ her work has not undergone significant changes, remaining essentially "qualification-based." In the academic environment, a contradiction has developed, which is expressed in two aspects:

- between competence-oriented goals and technologies of teaching and monitoring of the students' progress and the approach used in all universities of the Russian Federation to assess the effectiveness of teachers' activities on the basis of qualification indicators;

- between the ideas related to the pedagogical culture of a professor as a set of professional and personal competences available in scientific publications [3-5] and the absence of a similar assessment system for professors, approved in any state legislative documents.

This contradiction does not allow to study reliably the competence-based changes in the professor's personality during the period of digital transformation, and also inhibits the process of organized professional development [6] and professor's self-development, personalization, self-actualization and self-realization [7].

Therefore, the relevance of our research is to study the changes that have occurred in the professor's system of competences during the period of digital transformation, as well as to determine effective forms of evaluating his/her professional activity.

\section{Materials and methods}

To write the article, theoretical methods were used (studying scientific literature on the problems of competences in general, the professor's competences, methods of competence assessment, etc.), as well as empirical methods (observation, conversation) during forced remote learning in March 2020 - February 2021.

The research involved 43 professors from 6 Russian universities, one university in Thailand and two European Universities. All professors have a work experience between 5 and 30 years in higher education.

In a remote learning environment, the professors had to learn a lot before they were ready to teach this knowledge to students. During group discussions on platforms Microsoft Teams, Zoom, etc., chair meetings, in informal correspondence, the professors expressed concern about the unpreparedness (technical, educational, psychological) to conduct distance learning and those skills, knowledge, competences, which they lacked in the beginning, but then they spoke positively about the gained experience and readily shared it with colleagues.

The article summarizes data on the assessment of professors' competences in the course of remote learning and after the transition to P2P mode.

\section{Results}

\subsection{The System of the Professor's Competences}

Over the past 20 years, scientists around the world have quite often turned to the study of the competences of university professors. There is a large number of research of the most important competences that determine the success of a professor in teaching [8], in the use of modern information technologies [9], the organization and management of the 
educational process as a whole [1;2]. However, in our opinion, the studies, in which an attempt is made to identify and systematize the entire set of professional competences, as well as psychological and personal qualities of a professor, are of the greatest interest.

In contrast to the Russian pedagogical school, which uses the term "professional pedagogical culture of a teacher," the researchers in other countries prefer to speak of an "effective teacher" $[1 ; 10]$.

Most scientific research on the university professor's competences uses a descriptive approach to outlining the main professional duties of a scholar, the required skills and work functions, which if taken together can provide a high level of teaching, comfortable conditions for interacting with students, as well as become the basis for personal growth and development $[2-4 ; 11]$. At the same time, if the authors use the name of any competence, then it is the most common one mentioned in almost every article, for example, assessment competence, information competence, didactic / educational competence, etc.

It should be noted that in the documents of the European Commission on Training and Education, attempts have repeatedly been made to present a system of teacher's competences that will be uniform and common for the entire European educational space (without highlighting the type of educational institution). However, due to the fact that each country of the European Union uses its own methodological and practical approaches to the definition of competences, as well as there are significant differences in the naming of the competences, this turned out to be quite difficult. Meanwhile, the European Commission managed to identify broad basic competence areas, which were then proposed to break down into specific subject profile requirements [12, p. 20].

Studies of such basic competence areas allow us to present the complex professional activity of a university professor in all its integrity, continuity and focusing on the implementation of the main idea - the preservation of global culture and the creation of conditions for improving the economy and the population's quality of life.

In one of our previous works, we have described the following system of professional and personal competencies of a university professor:

- adaptational-and-civilizational competence,

- communicative,

- value-semantic,

- social-and-organizational,

- professional,

- social competences [5, p. 123].

The researcher K. Selvi lists the following basic professor's competences:

- field competencies,

- research competencies,

- curriculum competencies,

- lifelong learning competencies,

- social-cultural competencies,

- emotional competencies,

- communication competencies,

- information and communication technologies (ICT) competencies,

- environmental competencies [13, p. 138-139].

Despite some differences in naming, these systems of basic competence areas reflect the complex, multifactorial activity of a modern university professor and indicate that $\mathrm{s} / \mathrm{he}$ enters the educational process with his/her whole personality, since psychological qualities, skills of self-regulation of the emotional behaviour in the process of educational interaction with the students are no less important than, for example, information competences. 


\subsection{The changes in the competences, acquired during remote learning period}

Though the period of forced remote learning was relatively short in time, it has a major influence on the professors' perception of their role in education and development of their competences.

Before the pandemic started, we all witnessed a quantitative increase in certain skills and abilities as well as gradual development of competences, for example, this is how each of us gradually acquired new skills, which then helped to form the information competence. However, in the period of remote learning, taking into account the tightness of all events in time and the need to continue the educational process at all costs, the qualitative changes in the content of some of the professors' competences took place, and they also acquired some new skills.

Without setting the task of considering all changes in the system of competences in this article, we note that:

- the most significant transformations took place in information competence, as the new learning environment forced professors to learn not only to use new digital devices, applications and platforms, but also to change the choice of teaching methods;

- accordingly, the next competence, which has also undergone changes, is pedagogical or educational; today there are already many studies related to the didactics of e-learning, digital technologies for classroom and home activities;

- the communicative competence of the professor has also changed, since the professors sometimes had to communicate with the "black" screen, as the students did not have the opportunity or did not want to turn on their webcams. Due to the loss of the ability to perceive non-verbal signs, the professors listened especially carefully to intonation, also trying to modulate their voice. Their speech has become more concise and unambiguous;

- social-and-cultural competence turned out to be in great demand, since professors had to show special tact and empathy, asking students about their health and the state of their families, to be more flexible in discipline issues if, for example, they learned that students missed classes because they acted as volunteers [14].

In general, finding themselves in extreme conditions, most of the professors were able to quickly adapt and continue the educational process at a sufficiently high level.

\subsection{Assessment of the Professor's Competences}

The return to a regular face-to-face education has re-drawn attention to the need of finding ways to measure the efficiency and performance of university professors. First, the traditional practice of staff competition for vacant positions is being restored, as well as all other practices associated with obtaining an academic title, professional and corporative awards, etc.

In general, the practice of regular assessment of professors' performance allows:

- to increase their motivation for self-development and professional growth;

- raise professors' awareness of the need to constantly develop their competences;

- widen their teaching abilities and general culture;

- understand that new or developed competences provide a lot of opportunities;

- organize constantly working system of the quality assurance and control of professional activities.

It is known that the following tools and techniques are considered the most popular for professors' assessment:

- regular attendance of the lessons by other staff / classroom observations by peers or the Head of the Chair; 
- discussion of the attended lessons and professor's competences / peer review;

- self-assessment;

- individual development plans;

- students' feedback;

- video analysis / recorded lessons;

- professor's reports / essays;

- portfolio;

- career development procedure [5, p. 126-160; 12, p.37-38].

In the Fig. 1 the professors' attitude to the above mentioned assessment tools and techniques is shown.

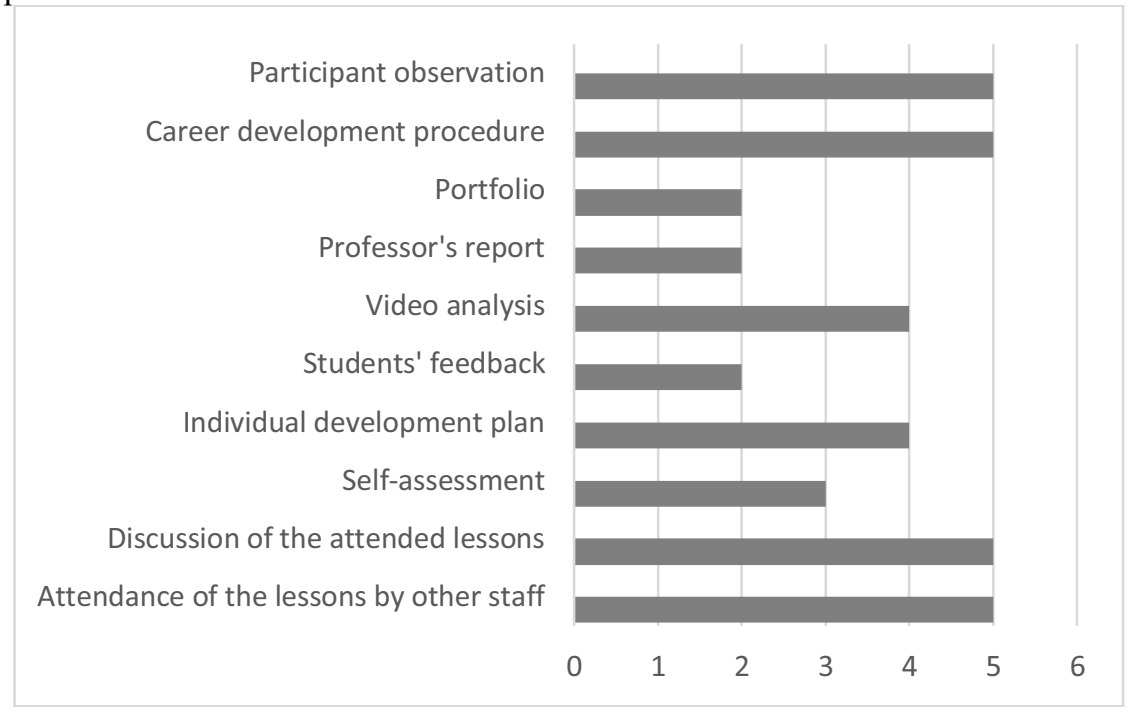

Fig. 1. The professors' attitude to the assessment tools and techniques.

A survey of professors' attitude to the assessment tools shows that they trust the quality and objectivity of evaluating their activities much more if the experts are persons who also have experience in educational, research, administrative, and other activities. Russian professors do not really believe in the correctness of assessment based on students' feedback or portfolio, since these forms are not traditional for universities in this country. However, their colleagues from Thailand note that they, in turn, are very attentive to the opinions of students, as this allows them to see themselves through the eyes of the younger generation, make adjustments of the content of the academic discipline and strive to improve the ways of interaction with students. This opinion coincides with the research of a group of Brazilian scientists N. Hein, A. Kroenke, M. R. J. Manoel who conducted a serious professors' assessment using multi-criteria decision analysis on the basis of the feedback of a large group of students [15].

The respondents note that during the period of remote learning, the same information technologies that were popular in the educational process with the students have become a new source of assessment tools for the professors' teaching activity and communication. For example, it became much easier to use the "video analysis" method, since it became possible to record either a whole lesson or its separate segments thanks to the available functions of conference platforms Zoom, Microsoft Teams, etc., and then discuss this video with colleagues in order to determine the correct use of teaching methods or technologies.

Professors and especially heads of the chairs consider "participant observation" to be a highly effective technique for assessing and improving pedagogical qualifications, since thanks to the modern digital technologies, they could virtually attend about ten classes 
during 2 hours and get a general impression of the technologies that their colleagues use on the lessons, obtain some valuable experience, learn about new functionalities of conference platforms, etc.

According to the respondents, it is the use of these two methods: "video analysis" and "participant observation", that makes it possible to notice changes in the competencies of the professors, to identify these new features in their pedagogical behaviour, communication with students, which did not exist before and which testify certain changes in the system of professional competencies in the conditions of digital transformation.

\section{Discussion}

The tools and techniques of professor's assessment are widely used and far from being new. However, the digital transformation of higher education requires introduction of more efficient tools for the above mentioned purpose.

In our opinion, regular "Contests of pedagogical excellence" can become a very fruitful way to perfect the procedure of professor's assessment and make it useful for a large group of people.

Our opinion is based on the positive experience of introducing such contests in some Russian universities. Unfortunately, the pandemic interrupted this process. But the idea to make the lessons - in any form: in "face-to-face" mode or in a recorded form - open and accessible for professors of different specialities, post-graduate students and young scientists, is very promising. These contests will enrich the faculty with new knowledge in educational methods and techniques, the colleagues will be able to acquire a useful experience of various aspects related to digitalization of modern education.

\section{Conclusion}

Continuing research in the field of identifying, describing and assessing the professor's competences, in our opinion, can contribute to:

1) improving the quality of future teachers' education, who must be ready to train a new type of specialists and cope with the challenges of the time;

2) an increase of the quality of education and a growth of the rating and attractiveness of the university;

3) the creation and implementation of the "Framework of Professor's Competences" in the educational system of each state, as well as the "Professional Standard for University Professors", which, in the context of global standardization and identification of qualification requirements for all specialties, is, on the one hand, a tool for managing the quality of education, and on the other hand, ensures this process is continuous;

4) a system of clear and transparent criteria for the professors' promotion and the improvement of the university personnel policy;

5) a qualitative change in the system of advanced training for professors and its transformation according to the principle of "life-long education" in order to constantly improve existing and acquire new competences;

6) the professor's finding of his/her role in the modern constantly changing world and in the conditions of ever-increasing demands on his/her work;

7) demonstration of the real potential of professional growth and self-development opportunities. 


\section{References}

1. S. Rama, Professor's Performance For Effective Teaching (Kosovo Case), International Conference on Education and Educational Psychology (ICEEPSY 2010). Procedia Social and Behavioral Sciences 12, 117-121 (2011). DOI:10.1016/J.Sbspro.2011.02.015

2. E. Elfrianto I. Dahnial, B. Tanjung, Jurnal Tarbiyah. 27 (1), 156-171 (2020). DOI: 10.30829/Tar.V27i1.704.

3. M. Blašková, R. Blaško, M. Jankalová, J. Radoslav, Procedia - Social And Behavioral Sciences 114, 466-475 (2014). Doi:10.1016/J.Sbspro.2013.12.731.

4. M. Blaskova, R. Blasko, E. Matuska, J. Rosak-Szyrocka, Development Of Key Competences Of University Teachers And Managers, 4th World Conference on Educational Technology Researches, WCETR-2014, Procedia - Social And Behavioral Sciences 182, 187 - 196 (2015).

5. V.D. Vereskun, T.E. Isaeva, University Professor in a Modern International Educational Environment: Qualification Requirements, Performance Assessment And Forms of Remuneration, Rostov-On-Don (2016) [In Russ.].

6. T.E. Isaeva, M.A. Kaplyuk, Revista Espacios 39 (43), 32-43 (2018).

7. T. Shcherbakova D. Misirov, T. Guseva, N. Alexandrova, Ye. Shostak, The Personality of the Future Teacher in the Context of the Challenges of the Innovation Space, E3S Web Conf. INNOVATIVE TECHNOLOGIES IN SCIENCE AND $\begin{array}{llll}\text { EDUCATION } & \text { (ITSE-2020). } & \mathbf{2 1 0} & \text { (2020). }\end{array}$ Https://Doi.Org/10.1051/E3sconf/202021018049.

8. Ch. Rapanta, L. Botturi, P. Goodyear, L. Guàrdia, M. Koole, Postdigital Science And Education 2, 923-945 (2020). Https://Doi.Org/10.1007/S42438-020-00155-Y

9. D.A. Mezentceva, E.S. Dzhavlakh, O.V. Eliseeva, A.Sh. Bagautdinova, Vysshee Obrazovanie v Rossii, Higher Education In Russia 29 (11), 88-97 (2020). DOI: Https://Doi.Org/10.31992/0869-3617-2020-29-11-88-97

10. V.-M. Cojocariu, G. Albu, Procedia - Social and Behavioral Sciences 116, 2611 - 2615 (2014).

11. C. Wardoyo, R. Firmansyah, Nuris, D.M. Sunaryanto, M.G. Satriyo, Wicaksono, Technium Social Sciences Journal, Technium Science 14 (1), 66-78 (2020).

12. Supporting Teacher Competence Development: for Better Learning Outcomes. European Commission: Training and Education (2013). Https:/Ec.Europa.Eu/Assets/Eac/Education/Experts-Groups/20112013/Teacher/Teachercomp_En.Pdf

13. K. Selvi, International Journal of Philosophy of Culture and Axiology, VII, (1) (2010). DOI: $10.5840 /$ Cultura20107133

14. T.E. Isaeva, Proceeding of the 17-Th International Conference the Teacher of a Higher School in the 21-St Century, Rostov-On-Don: 26-32 (2020).

15. N. Hein, A. Kroenke, M.R.J. Manoel, Information Technology and Quantitative Management (ITQM 2015), Procedia Computer Science 55, 539-548 (2015). 